Seção Temática: Os Recursos Públicos em Disputa

Volume 11 - $2021 \mid$ n. 30

\title{
Escolas charter e o novo FUNDEB: um necessário obstáculo à privatização e as tentativas de derrubá-lo
}

\author{
Henrique Dias Gomes de Nazareth \\ Universidade Federal do Estado do Rio de Janeiro (UNIRIO), Rio de Janeiro/RJ - Brasil
}

\section{Resumo}

Este artigo parte de um fato provocador: a tentativa de mudança do FUNDEB a fim de ampliar a privatização de seus recursos. O objetivo é entender como o FUNDEB tem sido um obstáculo para a implementação de escolas charter no Brasil. Por meio de uma análise documental, iremos analisar essa e outras iniciativas que visavam mudar as regras do fundo. No texto será possível encontrar: uma descrição detalhada da tentativa de inclusão de entidades privadas no Novo FUNDEB; um escrutínio das ações passadas ocorridas no âmbito do legislativo que pretendiam o mesmo objetivo; e a exposição de um programa que inicialmente pretendia utilizar recursos do FUNDEB em escolas charter. Conclui-se evidenciando que as regras do FUNDEB são barreiras importantes ao movimento pró-charter no Brasil e que o contexto legislativo é um importante campo de disputa. Entender esses entraves é essencial para um movimento de resistência em favor da defesa do direito à educação.

Palavras-chave: FUNDEB. Escolas Charter. Privatização da Educação. Organizações Sociais e Educação. Financiamento da Educação.

\section{Charter schools and the new FUNDEB: the necessary obstacle to privatization and the attempts to overthrow it in Brazil}

\begin{abstract}
This article departs from a provocative fact: the tentative of FUNDEB to allow the privatization of its resources. The objective is understand how FUNDEB has been an obstacle for the implementation of charter schools in Brazil. Through a documental analysis, we also review other initiatives that aimed to change the rules of the fund. The text is divided into the following sections: a detailed description of the attempt to include private entities in the new FUNDEB; a scrutiny of past actions that occurred in the legislative branch that intended the same goal; and the exposition of a program that initially tried to use FUNDEB resources in charter schools. We conclude by showing that the FUNDEB rules are significant barriers to the pro-charter movement in Brazil and that the legislative context is an important area of dispute. Understanding these obstacles is essential for a resistance movement in favor of defending the right to education.
\end{abstract}

Keywords: FUNDEB. Charter Schools. Privatization of Education. Social Organizations and Education. Funding for Education. 
Escolas charter e o novo FUNDEB

\section{Introdução}

Este artigo está inserido no contexto de uma pesquisa que investiga a proposição de escolas charter no Brasil. São chamadas de escola charter as escolas privadas ou de gestão privada financiadas com verbas públicas para oferecerem vagas para a população. Os modelos de charter são diversos e variam de acordo com a legislação e o contexto local. A diminuição da burocracia é vista como promotora de autonomia e eficiência. Todavia, essas escolas são reguladas pelos seus resultados, principalmente em exames de larga escala, dentro da lógica da concorrência de mercado.

Alguns dos defensores das charter alegam que não se trata de privatização. Afinal, não há venda de escolas públicas para a iniciativa privada e as escolas permanecem sendo gratuitas ${ }^{1}$. Entretanto, trabalhamos aqui com um entendimento mais amplo do fenômeno. No contexto internacional, esse tipo de escola "[...] se configura em uma modalidade de privatização da oferta educativa, tendo em vista se tratar de um mecanismo de subsídio público a instituições geridas por setor privado, o qual vem sendo proposto, por fundações e setores governamentais, como alternativa para a educação básica no Brasil" (ADRIÃO, 2014, p. 1).

Pesquisas como Adrião (2018a) apontam para as diferentes formas de privatização da educação pública. Analisando a literatura nacional e internacional disponível entre 1990 e 2014, a autora apresenta uma síntese dos processos de privatização que vêm ocorrendo no Brasil e os classifica de três maneiras: privatização da oferta; privatização da gestão; e privatização do currículo. No caso da oferta, incluem-se o crescimento do "[...] financiamento público, aumento de matrículas em estabelecimentos particulares e introdução de políticas ou programas de escolha parental" (ADRIÃO, 2018a, p. 11). No âmbito da privatização da gestão, estão as "[...] modalidades de subsídio público à oferta privada não associadas a políticas de escolha parental" (ADRIÃO, 2018a, p. 8). Já no domínio da privatização do currículo estão a compra e adoção de desenhos curriculares, tecnologias educacionais e sistemas privados de ensino.

As charter em seu formato original se enquadram principalmente na primeira dimensão, a privatização da oferta relacionada às políticas de escolha parental, enquanto os programas brasileiros (como o Programa de Contratos de Gestão de Goiás que será abordado mais adiante), apesar de se proclamarem inspirado nas charter schools, estão mais relacionados à privatização da gestão da educação pública.

A privatização da gestão no Brasil resulta da mudança do marco regulatório que se seguiu após a Constituição da República Federativa do Brasil de 1988, principalmente com a Emenda Constitucional $n^{\circ} 19$ de 1998 "[...] a partir da qual instituições privadas associam-se a governos por meio de diferentes mecanismos como contrato de gestão; termos de parceria, acordos de colaboração e de fomento e as parcerias público-privadas propriamente ditas" (ADRIÃO, 2018a, p. 17). Somando-se a isso, a aprovação da Lei no 13.019 de 2014, conhecida como Marco Regulatório das Organizações da Sociedade Civil (MROSC), buscou aperfeiçoar o ambiente jurídico e institucional, além de fornecer mais segurança para essa

\footnotetext{
1 Argumento encontrado em SEDUCE-GO (2016) que se refere à tentativa de implementação de escolas
} inspiradas nas charter em Goiás. 
relação, instituindo ou aprimorando instrumentos como o termo de colaboração, termo de fomento e acordo de cooperação (CRUZ, 2014).

O principal objetivo aqui é discutir e compreender como o Fundo de Manutenção e Desenvolvimento da Educação Básica e de Valorização dos Profissionais da Educação (FUNDEB) tem servido de obstáculo para uma maior implementação de modelos semelhantes às charter no ensino fundamental e no ensino médio. Cumpre ressaltar que entender os entraves enfrentados por aqueles que defendem esse formato de privatização é um aspecto importante para o movimento de resistência a tal modalidade, em favor da defesa do direito à educação.

Adota-se aqui a perspectiva constitucional do direito à educação como "[...] pleno desenvolvimento da pessoa, seu preparo para o exercício da cidadania e sua qualificação para o trabalho" (BRASIL, 1988). Assim como o entendimento da Campanha Nacional pelo Direito à Educação, que reivindica o caráter público, equitativo, universal, gratuito, inclusivo, laico, livre e de qualidade (CNPE, 2021). Esse posicionamento se faz necessário, pois, como explica Cara (2019), muitas políticas educacionais têm apresentado ideias diferentes sobre o direito à educação, inclusive indo em direção oposta aos princípios para a educação nacional proclamados na Constituição Federal de 1988.

Diante disso, um fato motivou a elaboração deste texto. A mais recente tentativa de mudança do FUNDEB a fim de ampliar o repasse de verbas públicas para a iniciativa privada. Trata-se da aprovação na Câmara dos Deputados da lei de regulamentação do Novo FUNDEB, que incluiria as escolas filantrópicas, comunitárias e confessionais entre aquelas habilitadas a receber os recursos públicos em toda educação básica². Posteriormente, o texto aprovado na Câmara foi revogado no Senado. História que será narrada ao longo do texto com mais detalhes.

Esse evento incitou importantes discussões sobre a laicidade da educação pública, porém, avaliamos que pouco repercutiu a respeito dos riscos de expansão de escolas inspiradas nos modelos charter nas redes públicas brasileiras. Por isso, o presente texto irá enveredar por esse caminho.

Apesar da vitória representada pela retirada dos destaques no Senado, não foi a primeira vez que se tentou incluir matrículas de escolas privadas no cômputo das vagas financiadas pelo FUNDEB no ensino fundamental e no ensino médio. É provável também que não seja a última vez que se faça tal tentativa. É aí que reside a importância deste artigo.

Além disso, em nossos estudos sobre as charter no Brasil, temos identificado que a impossibilidade de uso de recurso dos fundos no ensino fundamental e no ensino médio é um dos importantes obstáculos à expansão de modelos inspirados nas charter em nosso país. $\mathrm{O}$ FUNDEB, instituído pela Lei no 11.494/2007, permite apenas a distribuição de recursos para entidades privadas no caso das vagas oferecidas em creches, na educação no campo e na pré-escola, até a universalização prevista no Plano Nacional de Educação (Lei $n^{\circ}$ 13.005/2014). Ou seja, nos casos em que existe ausência de oferta por parte do poder público. Mudanças como aquelas propostas na Câmara poderiam permitir que a iniciativa privada sem

2 As regras antigas do FUNDEB (Lei no 11.494/2007) já permitiam a distribuição de recursos para entidades privadas, porém, apenas na creche, na pré-escola e na educação no campo. Ou seja, em casos de ausência de oferta na rede pública. 
fins lucrativos assumisse a gestão de escolas públicas já em funcionamento em toda educação básica, mesmo sem déficit de oferta.

Por meio de uma análise documental, analisamos essa e outras iniciativas que visavam a mudanças nas regras do FUNDEB para permitir a ampliação de modelos de conveniamento inspirados nas charter schools. Textos normativos foram fontes primárias que nos permitiram apreender e examinar os fatos e processos em pauta. Os textos desse tipo analisados foram: Brasil (2015; 2016; 2017; 2018 2019; 2020a); Goiás (2018); MP-GO (2016); Porto Alegre (2020) e SEDUCE-GO (2016). Somados aos textos normativos, debruçamo-nos também sobre reportagens e outros textos informativos que realizaram a cobertura desses fatos e proporcionaram o preenchimento de lacunas necessário para a interpretação do fenômeno estudado. Os textos informativos que se constituíram em fontes desta investigação foram: Caram e Brant (2020); Cássio e Moura (2021); Leão (2020); Mariz (2020); O Fundeb... (2020), Resende (2020); Siqueira (2020); Vasconcellos (2020) e Warth (2020).

Nas seções seguintes, será possível encontrar uma descrição mais detalhada da tentativa de inclusão de entidades privadas no escopo da regulamentação do Novo Fundeb. Após, serão apresentadas ações passadas ocorridas no âmbito do legislativo que pretendiam o mesmo objetivo. Em outra seção, descreveremos o caso do Programa de Contrato de Gestão de Goiás, que inicialmente pretendia utilizar recursos do FUNDEB em escolas geridas por Organizações Sociais (OSs). E, por fim, conclui-se evidenciando que as regras do FUNDEB se apresentam como uma barreira importante ao movimento de expansão das charter no Brasil e que o contexto legislativo se firma como campo de disputa de concepções de educação pública.

\section{Passando a boiada ${ }^{3}:$ o Novo FUNDEB e as emendas privatizantes}

No que tange ao financiamento da educação brasileira, 2020 foi um ano marcante. No mês de dezembro encerrava-se o prazo de vigência da Lei $n^{0} 11.494$ de 2007, que regulamenta o FUNDEB. Diante de tantos desafios enfrentados pelo País em decorrência da pandemia de COVID-19, a urgência em se aprovar uma nova regulamentação para a matéria era imperativa.

Especialistas, veículos de imprensa, políticos e gestores públicos alertaram para o risco de um "apagão educacional" caso o Novo FUNDEB não fosse aprovado e regulamentado em tempo hábil. Pois, o FUNDEB é responsável por $63 \%$ do financiamento da educação básica (VASCONCELLOS, 2020).

Ignorando a necessária urgência da pauta, o governo federal quis adiar a discussão por um ano e tentou modificar a proposta para incluir o Renda Brasil ${ }^{4}$ no escopo dos recursos do Novo FUNDEB. Essas sugestões estavam na contraproposta apresentada pelo governo aos líderes partidários antes do início da votação na Câmara da Proposta de Emenda à Constituição 15/2015 (PEC do FUNDEB). A relatora da PEC, deputada Professora Dorinha (DEM-TO), também chamou a atenção para a ameaça de "apagão", caso a vontade do governo prosperasse, e afirmou ainda que "[...] a ideia de remanejar recursos do fundo para

3 Referência a uma frase utilizada pelo Ministro do Meio Ambiente Ricardo Salles na reunião ministerial ocorrida em 22 de abril de 2020 (MINISTRO..., 2020).

4 Programa de assistência social que vem sendo elaborado pelo governo para substituir o Bolsa Família. No momento de redação deste artigo o programa não tinha sido implementado. 
Escolas charter e o novo FUNDEB

programas sociais é inconstitucional e certamente não será aprovada pela Câmara" (VASCONCELLOS, 2020, s. p.).

Com a ausência do Ministério da Educação no debate sobre o Novo FUNDEB, as iniciativas governamentais foram protagonizadas pelo Ministério da Economia, que tentou: evitar a ampliação da complementação da União ao fundo; desviar recursos para o já citado programa de assistência social (Renda Brasil) vinculado a um "voucher-creche" (CARAM; BRANT, 2020); e eliminar a vinculação mínima de $70 \%$ dos recursos destinados ao pagamento de profissionais da educação (CÁSSIO; MOURA, 2021).

Nenhuma dessas iniciativas do governo obteve êxito e após cinco anos de tramitação a PEC 15 de 2015 foi aprovada, transformando-se na Emenda Constitucional 108 de 2020 (EC 108/2020). Na ocasião, 499 deputados aprovaram o texto base e apenas sete se posicionaram de forma contrária. Esses sete deputados, apesar de serem identificados como bolsonaristas, contrariaram a orientação do governo, que, a despeito das tentativas já narradas, naquela altura já havia se conformado com a derrota e decidido orientar pela aprovação da PEC. Cássio e Moura (2020) demonstram que, para além de serem apoiadores do governo, os sete parlamentares também se assemelhavam por possuírem algum grau de envolvimento com o movimento reacionário Escola sem Partido.

A aprovação da PEC 15/2015 apresentou avanços para o financiamento da educação brasileira. Entretanto, a regulamentação do Novo FUNDEB ainda apresenta riscos. Entre os avanços, Jacomini e Pinto (2020) destacam: a garantia do caráter permanente do FUNDEB; a incorporação do conceito de Custo Aluno-Qualidade; a ampliação da complementação da União; a vedação da contabilização de gastos com profissionais da educação aposentados como manutenção e desenvolvimento do ensino; o modelo híbrido de distribuição de recursos da complementação da União; e a proibição do uso de receitas do salário-educação como fonte de recursos da complementação da União.

Os autores também ressaltam que, mesmo após a instituição da EC 108/2020, "[...] a construção do novo Fundeb, contudo, ainda está a meio caminho" (JACOMINI; PINTO, 2020, p. 2). Isso ocorre porque aspectos centrais do Novo FUNDEB ainda precisariam ser regulamentados. Entre esses pontos está a destinação de recursos do fundo para instituições privadas de ensino.

Poucos meses após a aprovação da EC 108/2020, a preocupação de Jacomini e Pinto (2020) se concretizou. Colocou-se em discussão o Projeto de Lei $n^{\circ} 4.372 / 2020$ (que regulamenta o FUNDEB) e uma série de emendas de cunho privatista foram apresentadas e aprovadas.

A sessão da Câmara, ocorrida em 10/12/2020, tinha como pauta a apreciação desse projeto de lei. Rompendo um acordo de consenso firmado entre situação, oposição e relator, o Deputado Felipe Rigoni (PSB-ES), parlamentares apresentaram e conseguiram aprovar destaques que permitiriam, inclusive, o pagamento de salário de terceirizados e profissionais contratados por essas entidades, sem vínculo com as redes públicas de ensino. Mesmo com deputados da base governista agindo contra o acordado, o relator demonstrou pouca resistência e os destaques foram apresentados.

Inicialmente, os destaques foram aprovados, entretanto, dias depois, em 15/12/2020, o Senado votou pelo retorno ao texto base, sem as emendas privatizantes. Posteriormente, uma nova sessão da Câmara, ocorrida em 17/12/2020, ratificou o que foi aprovado no Senado. 
A cobertura midiática desse debate foi centrada principalmente na questão das escolas confessionais ${ }^{5}$. O discurso da deputada Soraya Santos (PL/RJ), autora de uma das emendas privatizantes, revelava conversas com representantes da Igreja Católica e Evangélica e centrava-se na defesa da qualidade dessas escolas, afirmando que "[...] é preciso resgatar a verdade e falar que são escolas marista, salesianos, evangélicos, que sempre tiveram qualidade no ensino" (SIQUEIRA, 2020, s. p.). Assim, a deputada tentou separar as escolas religiosas de outras escolas privadas, como se a suposta "qualidade" delas as tornassem elegíveis para receber os recursos do FUNDEB. No intento de provar o seu ponto, Soraya ainda afirmava que a experiência pessoal que ela teve como aluna dos salesianos é a experiência que ela gostaria que todos tivessem (CÁSSIO; MOURA, 2021).

Apesar das inúmeras contradições desse discurso, o presente texto pretende chamar atenção para um ponto que pouco foi citado na sessão. As emendas propostas abriam caminhos também para a implementação de mais escolas charter no Brasil. A modificação que pretendia incluir escolas confessionais, filantrópicas e comunitárias de ensino fundamental e do ensino médio no FUNDEB seria um incentivo para a expansão em toda educação básica de modelos inspirados nas escolas charter.

Essa relação entre o FUNDEB e as escolas charter foi apontada por um dos gestores públicos que recentemente implementou o modelo no município de Porto Alegre ${ }^{6}$. Após a aprovação da PEC, Nelson Marchezan Júnior (PSDB/RS), prefeito de Porto Alegre entre 2017 e 2020, afirmou que o Novo FUNDEB é estatizante, empobrecedor e um crime contra as crianças brasileiras (O FUNDEB..., 2020).

Dizer que o Novo FUNDEB é estatizante se trata de um equívoco. Ele apenas não se tornou mais privatizante como queria o ex-prefeito. Afinal, o texto aprovado não flexibilizou as regras para permitir uma maior drenagem de recursos públicos para entes privados. Quanto a isso, as regras do antigo FUNDEB foram mantidas. As mesmas regras que condescenderam com o aumento do número de crianças em creches particulares conveniadas a partir de 2007 no município de São Paulo (FRANCO; DOMICIANO; ADRIÃO, 2019). Ou seja, registrou-se um aumento da rede privada conveniada quando a educação infantil foi incluída no FUNDEB, que antes financiava apenas o ensino fundamental por meio do Fundo de Manutenção e Desenvolvimento do Ensino Fundamental e de Valorização do Magistério (FUNDEF).

No caso das emendas proposta e aprovadas em um primeiro momento, especialistas da Associação Nacional de Pesquisa em Financiamento da Educação (FINEDUCA) e da Campanha Nacional pelo Direito à Educação (CNDE) calculavam que até 15,9 bilhões de reais das escolas públicas poderiam ser destinados ao setor privado (CNDE; FINEDUCA, 2020).

As modificações propostas pelos parlamentares permitiriam a transferência das verbas do FUNDEB para entes privados que ocorreriam não apenas na excepcionalidade de ausência de vagas em redes públicas. Os destaques visavam possibilitar que modelos de convênios substituíssem a oferta e a gestão pública da educação escolar por oferta e gestão privada, como pode ser observado no Quadro 1.

5 Mariz (2020), Resende (2020) e Warth (2020).

6 Nos referimos à rede de escolas comunitária de Porto Alegre, que já atendia a educação infantil e desde 2018 passou a atender o ensino fundamental, chamando estas de escolas charter. 
Quadro 1 - Destaques Aprovados Na Sessão Deliberativa Extraordinária Da Câmara Dos Deputados - 10/12/2020

\begin{tabular}{|c|c|c|}
\hline Destaque & $\begin{array}{l}\text { Resultado da } \\
\text { votação }\end{array}$ & Proposta \\
\hline 6 & $\begin{array}{l}\text { Aprovada. } \\
\text { Sim: } 258 ; \\
\text { não: } 180 ; \\
\text { total; } 438 .\end{array}$ & $\begin{array}{l}\text { A Emenda } n^{\circ} 40 \text {, de lavra da nobre Deputado Luisa Canziani (PTB-PR), inclui } \\
\text { as matrículas de educação profissional técnica de nível médio articulada e no } \\
\text { itinerário de formação técnica e profissional do ensino médio na distribuição } \\
\text { dos recursos do FUNDEB e permite parceria ou conveniamento dos serviços } \\
\text { nacionais de aprendizagem, das autarquias e fundações públicas para oferta } \\
\text { do itinerário de formação técnica e profissional do ensino médio aos } \\
\text { estudantes da rede pública. }\end{array}$ \\
\hline 8 & $\begin{array}{l}\text { Aprovada. } \\
\text { Sim: } 311 ; \\
\text { não: } 131 ; \\
\text { abstenção: } 1 \text {; } \\
\text { total: } 443 \text {. }\end{array}$ & $\begin{array}{l}\text { A Emenda } n^{\circ} 10 \text {, de lavra da nobre Deputada Soraya Santos (PL-RJ), } \\
\text { propõe, em relação ao Cômputo de matrículas, que sejam admitidos os } \\
\text { referentes ao ensino fundamental e no ensino médio regulares, limitadas } \\
\text { a } 10 \% \text { (dez por cento) do total de vagas ofertadas pelo ente federado em } \\
\text { cada uma dessas etapas de ensino. }\end{array}$ \\
\hline 9 & $\begin{array}{l}\text { Aprovada. } \\
\text { Sim: } 272 ; \\
\text { não: } 167 ; \\
\text { total: } 439 .\end{array}$ & $\begin{array}{l}\text { A Emenda } n^{\circ} 7 \text {, de lavra do nobre Deputado Eduardo Barbosa (PSDB-MG): - } \\
\text { acrescenta alínea f ao art. } 7^{\circ}, \S 3^{\circ}, \text { I, para efeito de distribuição dos recursos, o } \\
\text { cômputo das matrículas no contraturno, como complementação da jornada } \\
\text { escolar de estudantes matriculados na rede pública, para oferta de educação } \\
\text { básica em tempo integral; - prevê a ponderação para essa categoria no exercício } \\
\text { de } 2021(0,30) \text {. }\end{array}$ \\
\hline 1 & $\begin{array}{l}\text { Aprovada. } \\
\text { Sim } 205 ; \\
\text { não: } 198 ; \\
\text { total: } 403 .\end{array}$ & $\begin{array}{l}\text { A Emenda } n^{\circ} 20 \text {, de lavra da nobre Deputado Perpétua Almeida (PCdoB- } \\
\text { AC), prevê que o Poder público deverá fixar, em lei específica, até } \\
31 / 12 / 2021 \text {, piso salarial profissional nacional para os profissionais do } \\
\text { magistério público da educação básica considerando-se, até que seja } \\
\text { aprovada, o vigente disposto na Lei } n^{\circ} 11.738 / 2008 \text {. }\end{array}$ \\
\hline 4 & $\begin{array}{l}\text { Aprovada. } \\
\text { Sim: } 212 ; \\
\text { não: } 205 ; \\
\text { total: } 417 .\end{array}$ & $\begin{array}{l}\text { A Emenda } n^{\circ} 6 \text {, de lavra do nobre Deputado Tiago Mitraud (NOVO-MG): inclui } \\
\text { no conceito de profissionais da educação, os terceirizados e os de instituições } \\
\text { comunitárias, confessionais ou filantrópicas sem fins lucrativos conveniadas } \\
\text { com o Poder Público; - em relação ao conceito de efetivo exercício, suprime a } \\
\text { expressão "associada à regular vinculação contratual, temporária ou } \\
\text { estatutária, com o ente governamental que o remunera". }\end{array}$ \\
\hline
\end{tabular}

Fonte: Brasil (2020a).

No cerne das mudanças propostas está a equivocada ideia de que basta reduzir a burocracia pública ${ }^{7}$ para melhorar a qualidade da educação. Ou melhor, um discurso que tenta convencer a todos que a gestão privada tem mais competência para lidar com os problemas da escola pública. O fato é que esse assunto precisa ser discutido de uma forma muito mais responsável. Da maneira como foi apresentado na Câmara, sem evidências e embasado em experiências pessoais e discursos populistas, faltaram elementos para comprovar os benefícios da desburocratização na qualidade da educação.

A métrica comum que geralmente fundamenta a alegação de que as escolas privadas possuem qualidade superior costuma ser embasada em comparações de desempenho entre estudantes de escolas públicas e privadas em exames nacionais ou internacionais. Sobre esse pensamento, três aspectos nos parecem evidentes e contrariam o senso comum: (1) o desempenho escolar é afetado por fatores intraescolares, mas também por fatores extraescolares. Logo, não se pode atribuir apenas à escola a ocorrência de melhores resultados; (2) as escolas públicas enfrentam desafios plurais que podem ser distintos daqueles encontrados em escolas privadas. Assim, não há nada que indique que as entidades privadas que se propõem a gerir escolas públicas possuem experiência e conhecimento para lidar com essas questões. O problema é que, quando um governo está determinado a

7 Leia-se: concursos públicos, estabilidade do servidor público e licitações. 
privatizar a gestão de escolas, a inexistência de organizações privadas competentes pode ser ignorada em favor da crença ideológica na superioridade da gestão privada. Assim, Organizações Sociais com pouca ou nenhuma experiência podem ser qualificadas para assumir a gestão de escolas públicas ${ }^{8}$.

Caso os destaques não fossem revertidos no Senado, as emendas aprovadas, além de afrontarem a Constituição Federal (CNDE; FINEDUCA, 2020), iriam ampliar o processo de privatização da educação brasileira. Movimento que vem se intensificando ao longo dos anos e é identificado em pesquisa apresentada por Adrião (2018b).

Em resumo, todo esse processo teve um desfecho positivo para aqueles que acreditam que os recursos públicos devem ser investidos nas escolas públicas. O que, mesmo com algumas exceções, é uma conquista histórica consolidada na Constituição Federal de 1988 (SILVA; LIMA, 2009).

Mesmo com o desenlace dessa história, permanece a necessidade de alerta. Após a derrota, a deputada Joice Hasselmann (PSL/SP) declarou que "[...] essa discussão será retomada por medida provisória, porque o ministro da Educação é favorável, ou por um novo projeto de lei" (SIQUEIRA, 2020).

É possível, portanto, que essa não tenha sido a última tentativa dessa natureza. Tornase necessário resgatar eventos anteriores no âmbito do legislativo. $O$ que será feito na próxima seção.

\section{Tanto bate até que fura? outras iniciativas para incluir escolas charter no FUNDEB}

A tentativa de permitir o uso de verbas do FUNDEB por entidades privadas em toda educação básica relatada anteriormente não foi uma iniciativa isolada. Existiram outros movimentos que intencionavam remover essa barreira, que impede uma maior expansão de modelos inspirados nas charter.

Por isso, as emendas privatizantes ao texto de regulamentação do FUNDEB fazem parte de um contexto de tentativas de implementação de modelos semelhantes às charter no Brasil. Além desse, é possível identificar outros dois momentos semelhantes.

O primeiro nos remete ao Projeto de Lei do Senado $n^{\circ} 739$ de 2015, de autoria do Senador Cristovam Buarque (à época, do PDT). O senador pretendia inserir mecanismos legais de distribuição dos recursos do FUNDEB para Organizações Sociais (OSs) e citava a escola charter como forma de introdução de práticas modernas de gestão nas escolas públicas. Para o autor do PLS, o repasse para as OSs:

Poderá contribuir para a melhoria da qualidade da educação, na medida em que a utilização do contrato de gestão, previsto na Lei n 9.637, de 15 de maio de 1998, permitirá a introdução de práticas modernas de gestão na educação. Com efeito, o emprego mais eficiente dos recursos humanos e financeiros e o estabelecimento de metas de

8 Foi o que aconteceu na tentativa de implementação de escolas charter em Goiás. As Organizações Sociais foram incapazes de comprovar experiência relevante em educação. As organizações selecionadas tinham sido qualificadas na véspera do lançamento dos editais e eram compostas por pessoas ligadas a Organizações Sociais que atuam na área da saúde (NAZARETH, 2019). 
Escolas charter e o novo FUNDEB

desempenho propiciarão a melhoria do processo de ensino-aprendizagem nas escolas e, consequentemente, a melhoria dos indicadores da educação (BRASIL, 2015, p. 2).

Ainda na justificativa do PLS, as charter schools são citadas como modelos semelhantes ao que se quer regulamentar, assim como se menciona também os exemplos de países como Estados Unidos, Reino Unido, França, Austrália, Japão e Nicarágua. A única iniciativa brasileira citada é o PROCENTRO, programa implementado em Pernambuco entre 2004 e 2007 (SARDINHA, 2013). Em 2018, o projeto foi arquivado enquanto paralelamente já se discutia o Novo FUNDEB.

Outra tentativa ocorreu durante tramitação da PEC 15/2015. A Emenda $n^{\circ} 3$ foi apresentada pelos deputados Tiago Mitraud (NOVO/MG) e Marcelo Calero (CIDADANIA/RJ) ainda na Comissão Especial. Eles pretendiam converter parte dos recursos do FUNDEB para o financiamento de instituições privadas, inclusive com fins lucrativos. A tentativa favoreceria a expansão de charter e vouchers que são citados na justificativa da emenda.

O financiamento da Educação pública através de organizações privadas não é um tema alheio ao Fundo da Educação Básica (FUNDEB). Pelo contrário, desde 2007, os recursos do FUNDEB já podem ser destinados a creches e pré-escolas particulares. Nesse sentido, esta proposta pretende permitir que os estados e municípios possam direcionar parte dos recursos do FUNDEB para organizações da sociedade civil e para financiar bolsas de estudo em instituições de ensino privadas nos níveis da Educação Básica (ensino fundamental e médio) (BRASIL, 2019, p. 2, grifo nosso).

Chama atenção o desconhecimento a respeito da organização da educação brasileira, visto que os autores pretendiam modificar uma Proposta de Emenda à Constituição. Como se observa na citação supracitada, além de errar o nome do fundo, o texto de justificação da emenda confunde os níveis com etapas. Pois, o art. 21 da LDB é cristalino ao discriminar que a educação escolar se compõe de apenas dois níveis: educação básica; educação superior. Ensino fundamental e ensino médio são etapas que integram o primeiro nível, assim como a educação infantil.

Os deputados reconhecem que parte dos recursos do FUNDEB já são destinados às creches e pré-escolas particulares, mas pretendiam ampliar esse financiamento para toda a educação básica. Assim, trata-se de uma defesa da privatização como solução para a melhoria do serviço educacional. Por outro lado, o que o antigo FUNDEB já permitia era o financiamento de entes privados em casos de ausência de oferta por parte do Estado. Ainda no texto, os parlamentares afirmavam que:

\begin{abstract}
Permitir que crianças de famílias em situação de vulnerabilidade social também tenham acesso a um ensino de qualidade enquanto se busca soluções para elevar o desempenho das escolas públicas é também uma questão de justiça social. É por isso que é importante explorar inovações no modelo de ensino no Brasil, como oferecer bolsas em instituições de ensino privadas para alunos da rede pública e permitir a expansão das escolas conveniadas (chamadas de 'charter schools'). A vantagem destas escolas é que elas trazem os benefícios da gestão privada para as escolas públicas (BRASIL, 2019, p. 2).
\end{abstract}

Importante destacar aqui que a proposição de charter nesse contexto se dá por argumentos diferentes daqueles utilizados para justificar os convênios na educação infantil. Quando a discussão se dá no âmbito do ensino fundamental e médio, a questão do desempenho em exames censitários (confundido com qualidade) se torna central.

Em tese, os convênios firmados com entidades filantrópicas e confessionais para atendimento da oferta educacional na educação infantil compartilham de parte dos princípios 
das charter estadunidenses. Adrião (2017) explica que o modelo apresentado no Brasil como charter "[...] nada mais é que a ampliação para outras etapas de escolaridade do precário atendimento por convênios existentes na educação infantil” (ADRIÃO, 2017, p. 11).

Esses convênios costumam ser empregados mais como meios de suprir a ausência de vagas do que como alternativas supostamente mais eficientes. Até porque, mesmo após décadas de conveniamento na educação infantil, não se pode afirmar que a qualidade dessas escolas é superior. Alguns estudos vão demonstrar o contrário.

Franco, Domiciano e Adrião (2019) analisam as implicações da expansão da oferta de creche conveniada no município de São Paulo e concluem que a qualidade ${ }^{9}$ das creches $^{2}$ públicas se mostra superior se comparada com a qualidade das conveniadas.

Mesmo sendo prática consolidada na educação infantil, os defensores das charter pouco citam esses convênios quando pregam a favor da implementação do modelo. Geralmente utilizam o discurso da inovação e da gestão gerencial e dizem se inspirar nas experiências internacionais. Talvez isso possa ser explicado pela constatação de que as creches conveniadas não são necessariamente melhores do que as públicas. Afinal, assumir que já temos modelos semelhantes no Brasil há décadas sem resultados expressivos depõe contra a ampliação do modelo para as outras etapas de escolaridade.

De acordo com o Censo da Educação Básica 2019: na educação infantil 8,2\% das matrículas estão sob a responsabilidade da rede privada conveniada. Nas outras etapas da educação básica, esse número cai drasticamente, nos anos iniciais do ensino fundamental são apenas $0,74 \%$; nos anos finais do ensino fundamental são $0,3 \%$ das matrículas e, no ensino médio, registra-se o mesmo percentual, $0,3 \%$. O mesmo censo também evidencia que de 2015 até 2019 a rede conveniada vem decrescendo sensivelmente ${ }^{10}$ (BRASIL, 2020b).

Diante disso, uma pergunta se coloca: há diferenças entre charter e convênios? Podese dizer que, em termos de fundamentos, não. Os formatos de charter são tão diversos que é possível seguramente afirmar que convênios, contratos de gestão, parcerias públicoprivadas, termos de colaboração e qualquer outro instrumento jurídico brasileiro de transferência de parte das responsabilidades do Estado pela gestão de escolas para o setor privado podem ser enquadrados nessa perspectiva.

Entretanto, há que se considerar que os contextos diferentes de cada país contribuem para que a privatização por essa via seja mais representativa nos EUA do que no Brasil. Lá, o pleito pela escolha escolar impulsionou o movimento das charter. Aqui, os convênios foram empregados para suprir a falta de vagas na rede pública. O que muda, mais recentemente, é que modelos inspirados nas charter passaram a ser implementados no ensino fundamental e no ensino médio e apresentados por formuladores de políticas como alternativas para maior eficiência e melhoria de indicadores educacionais.

Retornando à questão da Emenda $n^{\circ} 3$, à semelhança do projeto de lei do Senado referido anteriormente, a emenda também apela para uma suposta qualidade superior das

9 O estudo utiliza critérios de qualidade inspirados no Custo Aluno Qualidade Inicial (CAQi), construído pela CNPE. As dimensões do CAQi são: Estrutura e funcionamento; trabalhadores e trabalhadoras da educação; gestão democrática; acesso e permanência.

10 Em 2015 o percentual de matrículas na educação infantil conveniada era de 9,58\%, em 2019 registrou-se 8,2\% (BRASIL, 2020b). 
instituições privadas. Além de apresentar os já antigos modelos de charter e vouchers ${ }^{11}$ como soluções inovadoras.

Por fim, a proposta não prosperou e o relatório apresentado pela Deputada Professora Dorinha Seabra Rezende (DEM-GO) votou pela inadmissibilidade da emenda $n^{\circ} 3$.

\section{Charter em Goiás: mais uma tentativa}

Nos últimos anos assistimos à implementação ou tentativa de modelos inspirados nas charter schools ${ }^{12}$. A iniciativa quantitativamente mais ambiciosa até 0 momento foi protagonizada pelo estado de Goiás no final de 2015. O governo de Marconi Perillo (PSDBGO) pretendia transferir a gestão de $30 \%$ das escolas básicas estaduais para Organizações Sociais. As OSs seriam responsáveis pela contratação de professores e outros funcionários via regime CLT em substituição aos profissionais temporários. Responderiam também por metas relacionadas aos índices de proficiência e às melhorias de infraestrutura.

Explicando de forma sucinta, o programa goiano não saiu do papel da forma como fora planejado, mas um modelo semelhante foi adotado nas escolas técnicas e profissionais. Entre os motivos para o insucesso das charter goianas está a resistência de sindicatos e estudantes e a contestação do Ministério Público de Goiás (MP-GO), que enxergou no programa inconsistências, como a violação do princípio de valorização do profissional da educação e da gestão democrática, falta de comprovação de idoneidade e competência por parte das Organizações Sociais e a impossibilidade de uso de verbas do FUNDEB.

Ao contestar o edital, que objetivava selecionar uma organização social para gerir 23 escolas da macrorregião de Anápolis, os procuradores do MP-GO alegaram que o governo não explicou como foi realizado o cálculo do valor por aluno a ser repassado, além de indicar a transferência de recursos do FUNDEB para que as entidades remunerassem os profissionais contratados, o que já não era permitido.

Todavia, o art. 22 da Lei Federal n. 11.494/2007, que regulamenta o FUNDEB, estipula que o pagamento da remuneração dos profissionais do magistério da educação com recursos do Fundo deve decorrer 'do efetivo exercício em cargo, emprego ou função, integrantes da estrutura, quadro ou tabela de servidores do Estado', ou seja, que esteja 'associada à sua regular vinculação contratual, temporária ou estatutária, com o ente governamental que o remunera' (MP-GO, 2016, p. 7).

O primeiro edital de chamamento previa a utilização de recursos do FUNDEB e receitas extraordinárias. Nele, os formuladores do programa goiano determinavam que a OS devia abrir uma conta corrente exclusiva para movimentação das verbas do fundo, além de impor, em contrato, que a organização devia renunciar ao sigilo bancário.

Fica evidente que o governo goiano acreditava poder utilizar o dinheiro do FUNDEB para remunerar os profissionais vinculados aos "parceiros" privados. Uma decisão do Supremo Tribunal Federal (STF) acerca de uma Ação Direta de Inconstitucionalidade (ADIN

11 Os vouchers foram propostos pela primeira vez em 1955, por Milton. As charter em 1974, por Ray Budde.

12 É possível citar o caso de Minas Gerais, onde a secretaria de educação anunciou a intenção de criar quatro escolas charter experimentais ainda em 2021 (LEÃO, 2020). Assim como o caso de Porto Alegre (2020), que desde 2018 ampliou a rede de escolas comunitárias de educação infantil realizando a contratualização de quatro escolas privadas para atender o ensino fundamental. Apesar de oficialmente serem chamadas de escolas comunitárias, há várias declarações de representantes da prefeitura se referindo a elas como escolas charter. 
$\left.n^{\circ} 1.923 / D F\right)$ endossando a contratação de professores via OSs era citada pelos formuladores da política como base legal da proposta. Entretanto, o entendimento do supremo não guarda nenhuma relação com as regras do FUNDEB, de forma que a contratação só pode ser realizada com recursos do tesouro, ou nas excepcionalidades já citadas neste texto.

A questão, além de ter sido objeto de contestação do MP-GO, também foi abordada pelo Sindicato dos Trabalhadores em Educação do Estado de Goiás (SINTEGO). O sindicato realizou uma consulta ao Fundo Nacional de Desenvolvimento da Educação (FNDE) sobre a utilização dos recursos e recebeu a resposta por meio da coordenadora-geral substituta, Aureli Oliveira Turra:

Os recursos repassados pelo FUNDEB devem ser aplicados [...] em ações consideradas de manutenção e desenvolvimento do ensino para a educação básica pública [...] sendo necessária a ressalva de que pelo menos $60 \%$ da totalidade dos recursos destina-se à remuneração dos profissionais do magistério público da educação básica, em efetivo exercício na rede pública e na esfera de atuação prioritária do ente federado, nos termos do artigo 22 da Lei 11.494 de 2007, que regulamenta o Fundeb (SINTEGO, 2016, p. 5 , grifo nosso).

A manifestação do FNDE também elucida o que a lei do FUNDEB define como profissional da educação: professores; profissionais que oferecem suporte pedagógico direto à docência; diretores escolares; orientadores educacionais e coordenadores pedagógicos. Já o efetivo exercício é definido como:

\begin{abstract}
Atuação efetiva no desempenho das atividades de magistério previstas no inciso II deste parágrafo associada à sua regular vinculação contratual, temporária ou estatutária, com o ente governamental que o remunera, não sendo descaracterizado por eventuais afastamentos temporários previstos em lei, com ônus para o empregador, que não impliquem rompimento da relação jurídica existente (SINTEGO, 2016, p. 5, grifo nosso).
\end{abstract}

Para o emprego da verba dos fundos o profissional deve estar vinculado diretamente ao ente federado. Nesse ponto, a Secretaria de Estado de Educação, Cultura e Esporte (SEDUCE-GO) foi obrigada a recuar, e nos editais publicados posteriormente foram realizadas alterações retirando a abertura da conta para movimentação de dinheiro do FUNDEB e explicitando que não seriam repassados recursos do FUNDEB para o ente privado, e que a OS não receberia recursos do FNDE/MEC.

$\mathrm{Na}$ Tabela 1 observa-se a relevância dos recursos do FUNDEB para a rede goiana. Apresenta-se aqui somente os dados referentes aos anos 2016, 2017 e 2018, pois eram os anos previstos para a implementação do programa.

Tabela 1 - Dotação Inicial e Recursos do Fundeb no Orçamento da SEDUCE-GO

\begin{tabular}{c|c|c|c}
\hline Ano & $\begin{array}{c}\text { Dotação inicial }{ }^{13} \\
\text { SEDUCE-GO }(\mathrm{R} \$)\end{array}$ & Recursos do FUNDEB (R\$) & Diferença $(\mathrm{R} \$)$ \\
\hline 2016 & $3.117 .102 .331,08$ & $1.844 .152 .332,09$ & $\mathrm{R} \$ 1.272 .949 .998,99(41 \%)$ \\
\hline 2017 & $3.353 .276 .128,89$ & $1.911 .143 .322,68$ & $\mathrm{R} \$ 1.442 .132 .806,21(43 \%)$ \\
\hline 2018 & $3.310 .862 .435,33$ & $1.949 .537 .955,03$ & $\mathrm{R} \$ 1.361 .324 .480,30(41 \%)$ \\
\hline
\end{tabular}

Fonte: Goiás (2018); Brasil, MEC (2016; 2017; 2018).

13 Dotação inicial - Valor do orçamento inicial fixado pela Lei Orçamentária, distribuído no âmbito da Unidade Orçamentária, no caso o Gabinete da Secretaria de Educação, Cultura e Esporte. 
É possível constatar que os recursos provenientes do fundo representavam mais da metade do orçamento da SEDUCE-GO. A diferença, ou seja, o percentual de recursos que não estavam vinculados ao FUNDEB, era da ordem de 41\% (2016), 43\% (2017) e 41\% (2018).

Dessa perspectiva, talvez fosse matematicamente possível transferir a gestão de $30 \%$ da rede para as Organizações Sociais mesmo sem os recursos do FUNDEB. O que não se aplica a qualquer rede de ensino, pois muitas não contam com outras fontes significativas de recursos. É preciso considerar ainda que, mesmo nas escolas geridas pelas OSs, uma parte dos professores (no mínimo 30\%) continuaria vinculada ao Estado, podendo ser remunerada pelo fundo.

O caso demonstra que a questão do FUNDEB criou uma dificuldade para a implementação e demandou um redesenho do programa, porém não se configurou em uma barreira intransponível, já que o Estado pôde remanejar o orçamento para pagar os contratos. Os motivos do fracasso do programa foram outros, que podem ser encontrados em Nazareth (2019). Porém, quanto maior a dimensão do programa, maior será a dificuldade de financiálo sem o uso desses recursos. $E$ isso explica as tentativas de mudar as regras do FUNDEB pela via legislativa que temos visto.

\section{Conclusão}

A lei de regulamentação do Novo FUNDEB aprovada em um primeiro momento na Câmara dos Deputados permitiria que até $10 \%$ das matrículas fossem ofertadas pela rede privada sem fins lucrativos. Na prática isso significaria a conversão de escolas públicas já em funcionamento em escolas do tipo charter, semelhante ao que foi tentado recentemente na rede estadual de Goiás.

Com os destaques aprovados, ocorreria o incentivo ao conveniamento em seus diferentes formatos. Inclusive aqueles mais inspirados nas escolas charter estadunidenses, que de maneira ideológica pressupõem que reduzir burocracias como concursos públicos e licitações é efetivo para o aumento da eficiência das escolas.

Há pelo menos duas fragilidades nesse argumento, uma delas é a medição da eficiência das escolas pela régua do desempenho em avaliações externas. A outra é a propaganda de uma suposta melhoria nos resultados educacionais que teria acontecido nos países onde as charter foram amplamente utilizadas. Mesmo após três décadas de charter nos EUA não há comprovação de que essas escolas são melhores.

Ao fim, a lei de regulamentação marcou uma derrota do movimento privatista. Porém, demonstramos aqui que houve outras tentativas de apropriação das verbas do FUNDEB e que a ameaça ainda permanece.

Este artigo procurou também evidenciar que as atuais regras do FUNDEB se apresentam como uma barreira importante ao movimento de expansão das charter no Brasil e que o contexto legislativo se firma como campo de disputa de concepções de educação pública.

Há recentemente a aprovação de um arcabouço legal que incentiva a privatização por meio da participação do setor privado sem fins lucrativos na provisão do serviço público. $O$ que é comemorado por aqueles que acreditam que a importação de modelos internacionais é capaz de resolver problemas nacionais e locais. Um exemplo é o Marco Regulatório das 
Organizações da Sociedade Civil (MROSC) aprovado pela Lei $N^{\circ} 13.019 / 2014$. O MROSC buscou aperfeiçoar o ambiente jurídico e institucional e fornecer mais segurança para a relação entre Estado e OSs.

Apesar desse contexto regulatório cada vez mais favorável ao movimento privatista, ainda há obstáculos. Ou seja, existem instrumentos de defesa da educação pública aos quais nós, educadores comprometidos com a qualidade social da escola, devemos nos apegar.

A atuação de entidades de educadoras e educadores organizados, que pressionaram senadores e forneceram informações técnicas para ilustrar as consequências das mudanças do FUNDEB, foi essencial para a organização de uma resistência em favor do direito à educação.

A Constituição Federal de 1988 é expressa em seu Art. 206 ao firmar princípios como a valorização dos profissionais da educação, com ingresso exclusivamente por concursos públicos; como a gestão democrática do ensino público; como o pluralismo de ideias; etc. As charter, com sua gestão privada de cunho gerencial atrelada a políticas de responsabilização, ameaçam todos esses princípios.

\section{Referências}

ADRIÃO, Theresa. Escolas Charters nos EUA: contradições de uma tendência proposta para - Brasil e suas implicações para a oferta da educação pública. Educação e filosofia, v. 28, p. 263-282, 2014.

ADRIÃO, Theresa. A privatização da educação básica no Brasil: considerações sobre a incidência de corporações na gestão da educação pública. In: ARAÚJO, Luiz; PINTO, José Marcelino Rezende (Org.). Público X privado em tempos e crise. São Paulo: Fundação Lauro Campos; Fineduca, 2017. p. 16-37.

ADRIÃO, Theresa. Dimensões e Formas da Privatização da Educação no Brasil: caracterização a partir de mapeamento de produções nacionais e internacionais. Currículo sem Fronteiras, v. 18, n. 1, p. 8-28, jan./abr. 2018a. Disponível em: http://www.curriculosem fronteiras.org/vol18iss1articles/adriao.pdf. Acesso em: 01 jun. 2018.

ADRIÃO, Theresa. Sobre a incidência do setor privado nas redes estaduais de ensino no Brasil: até onde os dados chegaram e o que se toma por fazer. In: GARCIA, Teise; ADRIÃO, Theresa (Org.). Currículo, gestão e oferta da educação básica brasileira: incidências de atores privados nos sistemas estaduais (2005-2015). Curitiba: CRV, 2018b.

BRASIL. Constituição da República Federativa do Brasil. Diário Oficial da União, Brasília, 1988. Disponível em: http://www.planalto.gov.br/ccivil_03/constituicao/constituicao.htm. Acesso em: 10 fev. 2021.

BRASIL. Senado Federal. Projeto de Lei do Senado № 739, de 2015. Brasília, 2015. Disponível em: https://legis.senado.leg.br/sdleg-getter/documento?dm=574888\&ts=1593 938175185\&disposition=inline. Acesso em: 17 abr. 2021.

BRASIL. MEC. Ministério da Educação. Portaria Interministerial Nº 8. Brasília, 2016.

BRASIL. MEC. Ministério da Educação. Portaria Interministerial № 10. Brasília, 2017.

BRASIL. MEC. Ministério da Educação. Portaria Interministerial № 6. Brasília, 2018. 
Escolas charter e o novo FUNDEB

BRASIL. Câmara dos Deputados. Emenda n 3 à PEC 15, de 2015. Brasília: Câmara dos Deputados, 2019. Disponível em: https://www.camara.leg.br/proposicoesWeb/p rop_mostrarintegra?codteor $=1760837 \&$ filename $=E M C+3 / 2019+P E C 01515+\% 3 D \% 3 E+P E C+$ 15/2015. Acesso em: 10 fev. 2021.

BRASIL. Câmara dos Deputados. Parecer às emendas de plenário oferecidas ao PL No 4.372 de 2020. Brasília: Câmara dos Deputados, 2020a. Disponível em: https://www.camar a.leg.br/proposicoesWeb/prop_mostrarintegra?codteor=1950028\&filename=PEP+2+\%3D\%3 $E+P L+4372 / 2020$. Acesso em: 10 fev. 2021.

BRASIL. Instituto Nacional de Estudos e Pesquisas Educacionais Anísio Teixeira (Inep). Censo da Educação Básica 2019: Resumo Técnico. Brasília, 2020b. Disponível em: https://download.inep.gov.br/publicacoes/institucionais/estatisticas_e_indicadores/resumo_te cnico_censo_da_educacao_basica_2019.pdf. Acesso em: 17 abr. 2021.

CARA, Daniel. Contra a barbárie, o direito à educação. In: CÁSSIO, Fernando (Org.). Educação contra a Barbárie. São Paulo: Boitempo, 2019. p. 25-32.

CARAM, Bernardo; BRANT, Danielle. Governo quer R\$ 6 bilhões do Fundeb para bancar 'voucher-creche' no setor privado. Folha de São Paulo, São Paulo, 20 jul. 2020. Disponível em: https://www1.folha.uol.com.br/educacao/2020/07/governo-quer-r-6-bilhoes-do-fundebpara-bancar-voucher-creche-no-setor-privado.shtml. Acesso em: 15 abr. 2021.

CÁSSIO, Fernando; MOURA, Fernanda. Como 163 deputados tentaram tirar dinheiro da Educação (e perderam). Entendendo Bolsonaro. Blogosfera UOL, São Paulo, 8 jan. 2021. Disponível em: https://entendendobolsonaro.blogosfera.uol.com.br/2021/01/08/como-163deputados-tentaram-tirar-dinheiro-da-educacao-e-perderam/. Acesso em: 17 abr. 2021.

CNDE. Campanha Nacional pelo Direito à Educação; FINEDUCA. Associação Nacional de Pesquisa em Financiamento da Educação. Nota Técnica: PL da Câmara sobre o Fundeb: retirando recursos de Estados, DF e Municípios e rasgando a Constituição. 2020. Disponível em: https://media.campanha.org.br/acervo/documentos/PautasPoliticas _Fundeb2020_NotaTecnica_2020_12_14_Campanha-Fineduca_final_1.pdf. Acesso em: 17 abr. 2021.

CNPE. Campanha Nacional pelo Direito à Educação. Como deve ser. 2021. Disponível em: https://campanha.org.br/. Acesso em: 17 abr. 2021.

CRUZ, Mauri J. V. Reflexões sobre o marco regulatório de acesso a recursos públicos pelas Organizações da Sociedade Civil Brasileira. In: SUARÉZ, Ana Lúcia; BOMFIM, Maciel; BORDIN Erica Bomfim (Org.). A Face Privada na Gestão das Políticas Públicas. 2014. Disponível em: http://www.participa.br/articles/public/0008/4321/Mauri_Cruz.pdf. Acesso em: 15 ago. 2019.

FRANCO, Dalva; DOMICIANO, Cassia Alessandra; ADRIÃO, Theresa. Privatização das creches em São Paulo e seus efeitos sobre a qualidade da oferta. Teoria e Prática da Educação, Maringá, v. 22, n. 3, p. 80-96, 2019. Disponível em: https://periodicos.uem.br/ojs/in dex.php/TeorPratEduc/article/view/50491. Acesso em: 30 jun. 2020.

GOIÁS. Goiás Transparente. Execução Orçamentária: Gabinete da Secretaria de Educação, Cultura e Esporte. 2018. Disponível em: http://www.transparencia.go.gov.br/l 
Escolas charter e o novo FUNDEB

ai.php?painel=execucao_orcamentaria_visao_g eral\&orgao=seduce. Acesso em: 19 set. 2019.

JACOMINI, Márcia Aparecida; PINTO, José Marcelino de Rezende. Apresentação da Seção Temática: Balanço do Fundeb. FINEDUCA - Revista de Financiamento da Educação, v. 10, 2020.

LEÃO, Sofia. Minas Gerais terá 4 escolas charter em 2021; entenda o modelo. BHAZ, Belo Horizonte, 14 set. 2020. Disponível em: https://bhaz.com.br/2020/09/14/minas-gerais-teraescolas-charter-2021-entenda-modelo/\#gref. Acesso em: 17 abr. 2021.

MARIZ, Renata. Bolsonaro quer que escolas ligadas a igrejas recebam verbas do Fundeb. $\mathbf{0}$ Globo, Rio de Janeiro, 9 out. 2020. Disponível em: https://oglobo.globo.com/sociedade/e ducacao/bolsonaro-quer-que-escolas-ligadas-igrejas-recebam-verba-do-fundeb-24682564.

Acesso em: 12 dez. 2020.

MINISTRO do Meio Ambiente defende passar 'a boiada' e 'mudar' regras enquanto atenção da mídia está voltada para a Covid-19. G1, Rio de Janeiro, 22 de mai. 2020. Disponível em: https://g1.globo.com/politica/noticia/2020/05/22/ministro-do-meio-ambiente-defende-

passar-a-boiada-e-mudar-regramento-e-simplificar-normas.ghtml. Acesso em: 17 abr. 2021.

MP-GO. Ministério Público do Estado de Goiás. Recomendação sobre a suspensão do edital 001/2016. Goiânia, 2016. Disponível em: http://www.mpgo.mp. br/portal larquivos/2016/02/16/17_36_26_430_Recomenda\%C3\%A7\%C3\%A30_MPE_MPF_e_MPC_ suspens\%C3\%A3o_edital_OSs_nas_escolas.pdf. Acesso em: 10 jan. 2017.

NATIONAL ALLIANCE FOR PUBLIC CHARTER SCHOOLS. National charter school facts. 2018. Disponível em: https://www.publiccharters.org/. Acesso em: 01 ago. 2018.

NAZARETH, Henrique Dias Gomes de. Escolas Charter e Contratos de Gestão na Educação: um estudo do programa de contratos de gestão com organizações sociais na rede goiana de educação básica. 2019. Tese (Doutorado em Educação) - Universidade Federal do Estado do Rio de Janeiro, Rio de Janeiro, 2019.

O FUNDEB aprovado pelo Congresso é um crime contra as crianças brasileiras, diz Nelson Marchezan Júnior. Revista Isto é, São Paulo, 9 set. 2020. Disponível em: https://istoe.com.br/o-fundeb-aprovado-pelo-congresso-e-um-crime-contra-as-criancasbrasileiras-diz-nelson-marchezan/. Acesso em: 17 abr. 2021.

PORTO ALEGRE. Gabinete do Prefeito. Carta aberta à população. Porto Alegre, 2020. Disponível em: https://prefeitura.poa.br/gp/noticias/carta-aberta-populacao. Acesso em: 10 abr. 2021.

RESENDE, Thiago. Câmara inclui escolas religiosas entre beneficiadas pelo Fundeb. Folha de São Paulo, São Paulo, 10 dez. 2020. Disponível em: https://www1.folha.uol.com.br/educa cao/2020/12/camara-aprova-texto-base-do-projeto-com-regras-para-o-fundeb.shtml. Acesso em: 15 abr. 2021.

SEDUCE-GO. Secretaria de Educação, Cultura e Esporte de Goiás. O que você precisa saber sobre as OSs na educação. Goiânia: SEDUCE, 2016. Disponível em: http://www.casacivil.go.gov.br/post/ver/206936/o-que-voce-precisa-saber-sobreas-oss-naeducacao. Acesso em: 6 jun. 2017. 
Escolas charter e o novo FUNDEB

SILVA, Ligiane Aparecida da; LIMA, Rosilene de. Florestan Fernandes na comissão de educação da constituinte: a luta pela escola pública, laica e gratuita no Brasil. In: CONGRESSO NACIONAL DE EDUCAÇÃO - EDUCERE, 9., 2009, Curitiba. Anais [...] Curitiba, 2009. Disponível em: https://educere.bruc.com.br/arquivo/pdf2009/3122_1859.pdf. Acesso em: 12 dez. 2020.

SINTEGO. FNDE confirma: recursos do FUNDEB são para pagar efetivos. 2016b. Disponível em: http://sintego.org.br/midias/downloads/08042016095655.pdf. Acesso em: 10 set. 2018.

SIQUEIRA, Carol. Deputada diz que discussão sobre Fundeb para filantrópica não se encerrou. Agência Câmara de Notícias, Brasília, 17 dez. 2020. Disponível em: https://www. camara.leg.br/noticias/717243-deputada-diz-que-discussao-sobre-fundeb-para-filantropicanao-se-encerrou/. Acesso em: 17 abr. 2021.

VASCONCELLOS, Jorge. Fundeb começa a ser votado hoje na Câmara. Correio Braziliense, Brasília, 20 jun. 2020. Disponível em: https://www.correiobraziliense.com. br/app/noticia/politica/2020/07/20/interna_politica,873528/sob-risco-de-nao-existir-em-2021fundeb-comeca-a-ser-votado-na-camara.shtml. Acesso em: 17 abr. 2021.

WARTH, Anne. Câmara aprova uso de recursos públicos do Fundeb para escolas ligadas a igrejas e ao Sistema S. O Estado de São Paulo, São Paulo, 10 dez. 2020. Disponível em: https://educacao.estadao.com.br/noticias/geral,camara-aprova-uso-de-recursos-publicos-dofundeb-para-escolas-ligadas-a-igrejas-e-ao-sistema-s,70003547859. Acesso em: 17 abr. 2021.

Henrique Dias Gomes de Nazareth é pedagogo, Mestre em Educação e Doutor em Educação pela Universidade Federal do Estado do Rio de Janeiro. Atualmente é professor do Departamento de Didática da UNIRIO. Tem experiência na área de pesquisa e educação, atuando principalmente nos seguintes temas: escolas charter, avaliação educacional, avaliação de larga escala, contratos de gestão na educação, privatização da educação e política educacional.

ORCID: https://orcid.org/0000-0002-9833-0010

E-mail: henrique.dias@edu.unirio.br 